\title{
Characterization of Photosystem I/Bio-Engineered Nanoparticle Complex System by Atomic Force Microscopy and Scanning Surface Potential Microscopy
}

\author{
I. Lee, ${ }^{*}$ J. S. Tabb, ${ }^{* *}$ C. Chase, ${ }^{* *}$ T. Kuritz, ${ }^{*}$ E. T. Owens, ${ }^{*}$ and E. Greenbaum* \\ *Oak Ridge National Laboratory, Chemical Science Division, Oak Ridge, TN 37831-6194 \\ **Agave Biosystems, 401 East State Street, Ithaca, NY 14850
}

\begin{abstract}
Atomic force microscope (AFM) [1] and scanning surface potential microscope (SSPM) [2] were used to characterize the construction process and the end-results of Photosystem I (PSI) reaction center/bio-engineered nanoparticle complex system. PSI reaction centers are nanometer-size robust supramolecular structures that can be isolated and purified from green plants. The PSI reaction center is a molecular diode [3] and photovoltaic device [4] made by nature. We have demonstrated that PS I can be selectively oriented by chemical modification of a surface without denatured [5]. The bacterial cell surface layer (s-layer) proteins are two-dimensional protein crystals of the outermost component of bacterial cell envelopes. The S-layer's intrinsic ability to self-assemble allows the formation of protein lattice in suspension, on lipid films, on liposomes, and on solid surfaces, such as silicon wafer, metals, and polymers [6,7]. The S-layer has been used as a mask to form two-dimensional $\mathrm{Au} / \mathrm{Pd}$ nanoparticle array on silicon wafer.
\end{abstract}

In this work, a complex system consists of PSI, 2-mercaptoethanol, $\mathrm{Au}$ or $\mathrm{Au} / \mathrm{Pd}$ nanoparticle, mercaptoethane, and $\mathrm{Au}\{111\}$ substrate was constructed, as shown in FIG. 1. The Au\{111\} thin film was epitaxially grown on mica substrate and then treated with the mercaptoethane to form a hydrophobic surface. The S-layer was then used as a mask to form 2-dimensional $\mathrm{Au}$ or $\mathrm{Au} / \mathrm{Pd}$ nanoparticle array on top of $\mathrm{Au}\{111\}$. This substrate was then treated with 2-mercaptoethanol and then immersed in PSI solution. The substrates of both $\mathrm{Au}$ and $\mathrm{Au} / \mathrm{Pd}$ were imaged by AFM before and after the PSI immobilization. Before the PSI immobilization, we observed the particle height of $2 \mathrm{~nm}$ for both $\mathrm{Au}$ and $\mathrm{Au} / \mathrm{Pd}$ substrate. This is consistent with the evaporation thickness and SEM measurement. While after the PSI immobilization, the particle height became $7 \mathrm{~nm}$ for PSI-Au nanoparticle complex system and $6 \mathrm{~nm}$ for PSI-Au/Pd nanoparticle complex system. The SSPM was used to measure the light-induced potential change on these complex systems. We observed a 19 $\mathrm{mV}$ (as shown in FIG. 2) difference in PSI-Au nanoparticle complex system and a $7 \mathrm{mV}$ difference in PSI-Au/Pd nanoparticle complex system. The variation in photo-induced potential difference between these two systems may be due to the difference in allowed energy states when the electron went through the double-barrier resonant tunneling from the substrate to the PSI.

\section{References}

[1] G. Binnig et al., Phys. Rev. Lett. 56 (1986) 930.

[2] M. Fujihara et al., Chem. Lett. (1992) 2223.

[3] I. Lee et al., Proc. Natl. Acad. Sci. USA 92 (1995) 1965.

[4] I. Lee et al., J. Phys. Chem. B 104 (2000) 2439.

[5] I. Lee et al., Phys. Rev. Lett. 79 (1997) 3294.

[6] D. Pum and U. B. Sleytr, Trends. Biotechnol. 17 (1999) 8.

[7] U. B. Sleytr et al., Angew. Chem. Int. Ed. Engl. 38 (1999) 1034. 


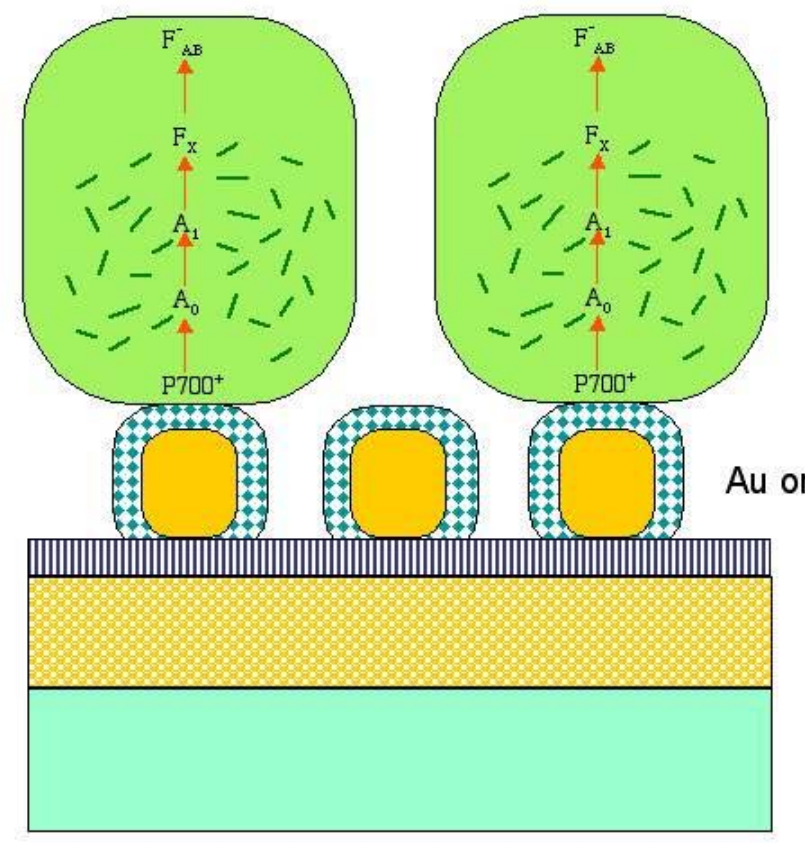

Photosystem I (PSI)

\section{2-mercaptoethhanol}

$\mathrm{Au}$ or Au/Pd nanoparticles

Mercaptoethane SAM

$\mathrm{Au}\{111\}$

Mica Substrate

FIG. 1. Photosystem I/Bio-Engineered Nanoparticle Complex System.
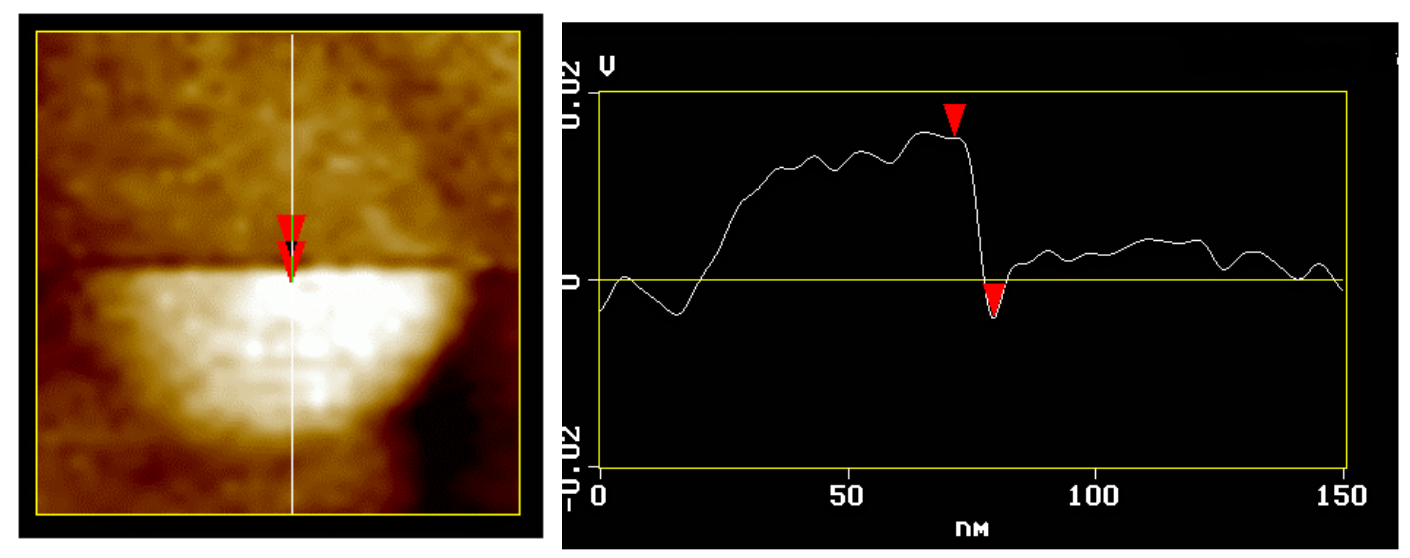

FIG. 2. SSPM measurement of photo-induced potential change in PSI +2-Mercaptoethanol+Nano $\mathrm{Au}+$ Mercaptoethane $+\mathrm{Au}\{111\}$ complex system, The vertical distance between two pointers is 19 $\mathrm{mV}$, 